\title{
BEHAVIOUR OF PERIWINKLE SHELL ASH BLENDED CEMENT CONCRETE IN SULPHURIC ACID ENVIRONMENT
}

\author{
I. C. Attah ${ }^{1, *}$, R. K. Etim ${ }^{2}$ and D. U. Ekpo 3

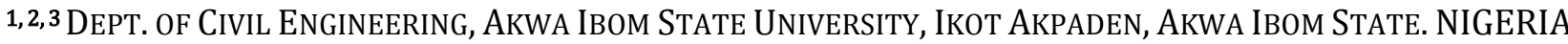 \\ Email addresses: ${ }^{1}$ attahimoh@gmail.com, ${ }^{2}$ rolandkufre24@gmail.com, ${ }^{3}$ david.ekpo13@gmail.com
}

\begin{abstract}
This paper presents the influence of sulphuric acid on compressive strength of concrete made with cement blended with periwinkle shell ash (PSA). The cement component was replaced with PSA at 0\%, $5 \%, 10 \%, 15 \%$ and $20 \%$. Concrete mix ratio of 1:2:4 and a constant water cement ratio of 0.6 was used. A total of 180 cube specimens (150mm $x 150 \mathrm{~mm} \times 150 \mathrm{~mm}$ ) were cast and tested for compressive strength at 7, 14, 21 and 28 days of immersion in potable tap water (as control) and (5\% and $10 \%$ ) sulphuric acid solutions. Test results showed that the compressive strength increased with age and decreased with PSA content for specimen cured in water (control); while for specimen cured in sulphuric acid solutions, the compressive strength decreased with age, PSA content as well as sulphuric acid content. The statistical analysis of variance showed that the sulphuric acid concentrations, PSA contents and curing age have effect on the concrete compressive strength. Regardless of the concentration of exposure conditions, it is concluded that PSA did not lighten the adverse effects of sulphuric acid on the compressive strength of cement blended with PSA.
\end{abstract}

Keywords: Cement, Compressive strength, Concrete, Periwinkle shell ash, Sulphuric acid.

\section{INTRODUCTION}

Concrete structures are constantly subjected to aggressive environmental conditions. Such interaction may be due to external and internal influences, thereby affecting the mechanical and physical properties of concrete [1]. The external factors include chemical attack or mechanical damage caused by impact, abrasion, erosion or cavitations; while the internal factors result from chemical reactions involving the concrete constituents [2]. The durability of concrete is measured by its ability to resist these factors or any other process of deterioration [3]. Some failures in concrete structures are as a result of inadequate durability which exhibit itself by deterioration, induced by external or internal factors within the concrete.

Concrete is susceptible to attack by sulphuric acid produced from either sewage or sulphur dioxide present in the atmosphere of industrial cities. This is due to the high alkalinity of Portland cement concrete, which can be attacked by other acids as well [4]. The acidic environment is deleterious to concrete durability because acid neutralizes the alkalinity of concrete by reacting with the hydration products of the concrete matrix to form gypsum and ettringite [5 - 9]. Both gypsum and ettringite possess little structural strength, yet they have larger volumes than the compounds they replace. This results in internal pressures, formation of cracks and eventually, the loss of strength [10]. Consequently, the concrete becomes vulnerable to aggressive exposure [11]. Sulphuric acid is particularly corrosive due to the sulphate ion participating in sulphate attack, in addition to the dissolution caused by the hydrogen ion [12]. The degree of concrete deterioration increases due to alternate wet-dry cycles of exposure to sulphuric acid and the rate of concrete deterioration along the penetration depth of sulphuric acid could be described by a variation in sulphur concentration with the depth of acid penetration [4].

As a remedy to this deteriorating effect induced by chemical attack on concrete, the development of acid resistant cementitious material using multiple mineral admixtures for the purpose of inhibiting the production of calcium hydroxide had been performed by Ookame et al [13]. Mineral admixtures have been used to partially replace cement in concrete $[14,15]$. Soeda [16] confirmed that the multiple uses of mineral admixtures can significantly reduce the erosion due to sulphuric acid attacks. Commonly used mineral 
admixtures have been fly ash, blast furnace slag, silica fume and rice husk ash. Ahmed and Munirudrappa [17] studied the effect of plasticizer addition on the workability and compressive strength of concrete. Their study showed that the addition of plasticizer enhances the resistance of concrete to sulphuric acid. The deterioration of concrete subjected to sulphuric acid attack increased with increase in cement content. Concrete with plasticizer showed better workability and compressive strength. Olonade et al [11] observed that the compressive strength reduced with the concentrations of sulphuric acid as well as with CPA content. Siad et al [18] showed that natural pozzolana had positive influence on the behaviour of Self compacting concrete under both sulphuric and hydrochloric acid curing mediums. Similarly, Adesanya and Raheem [19] reported that cement mixed with 15 $\%$ of Corn cob ash improved the concrete resistance to $\mathrm{H}_{2} \mathrm{SO}_{4}$ and $\mathrm{HCl}$ attack. Consequently the use of pozzolanas in concrete have been reported to mitigate the effect of sulphates and alkali - silica reaction, especially deleterious in concrete structures, by the development of a faster pozzolanic reaction [20].

Recently the use of periwinkle shell ash (PSA) as cementitious supplementary material in concrete and sandcrete block production had been reported by [21, $22,23]$. The use of PSA in concrete and its effect on the compressive strength up to hydration period of 28 days in potable water and crude oil environment was investigated by Etim et al [24]. The compressive strength performance of periwinkle shell ash (PSA) blended cement concrete exposed to $\mathrm{MgSO}_{4}$ and $\mathrm{NaSO}_{4}$ in 1,3 and $5 \%$ concentration was investigated by Umoh and Olusola [25]. They concluded that $10 \%$ PSA content is adequate as supplementary cementitious material for structural concrete to be placed in an aggressive sulphate environment. This study rather, examined the compressive strength performance of PSA blended cement concrete exposed to 5 and $10 \%$ $\mathrm{H}_{2} \mathrm{SO}_{4}$ environment. The objective is to determine the compressive strength of cement blended with PSA concrete cured in potable water and sulphuric acid media. It is thought that the understanding of the performance and evaluation of the resistance to sulphuric acid for concrete made from cement blended PSA can lead to the development of much higherquality acid resistant cementitious material.

\section{MATERIALS AND METHODS}

\subsection{Materials}

The periwinkle shells used for this study were obtained from a dump site at Ikot Ebido Oku, Uyo, Akwa Ibom State, Nigeria. The periwinkle shells was washed, air dried and calcined to a temperature of $1000^{\circ} \mathrm{C}$. The calcined shell was brought out of the oven, allowed to cool and grinded to powdered form. The PSA was sieved through BS sieve No 200. The specimen was then stored in a sealed water proof bag for preservation before use. The United Cement Company of Nigeria (UNICEM) Ordinary Portland Cement (OPC) was used. The cement conform to NIS 444-1 [26]. The X-Ray Fluorescence, XRF test was carried out on the PSA and cement specimens to determine their oxide composition. The fine aggregate (sand) was sourced from a river bed in Mkpat Enin, Akwa Ibom State, Nigeria. It was prepared to EN 12620 [27] requirements. The sand belongs to grading zone 2 according to the grading limits for fine aggregates BS 882 [28] with a fineness modulus of 3.33. The aggregate was free of deleterious materials. The coarse aggregate was crushed granite of maximum size $20 \mathrm{~mm}$ with specific gravity of 2.65 and in conformity to EN 12620 [27]. The water used throughout the duration of the research was potable tap water within Akwa Ibom State University campus. It satisfies the specification of water for use in concrete mixtures according to ASTM C1602-12 [29]. The Sulphuric acid was procured from an open market and different concentrations of its solution were prepared in the laboratory. Three separate curing media considered in this study were 0 $\%$ (control medium) $5 \%$ and $10 \%$ concentration of sulphuric acid

\subsection{Methods}

\subsubsection{Preparation of Concrete Samples}

A mix ratio of 1:2:4 at water cement ratio of 0.6 was adopted and batched in weight. Periwinkle shell ash was used to replace cement in concrete production. The levels of replacement of cement with PSA were at $0,5,10,15$ and 20 percent. A total of one hundred and eighty (180) samples of concrete cubes were cast, cured and tested. The study was carried out using target mean strength of grade $25 \mathrm{~N} / \mathrm{mm}^{2}$. The concrete cubes were cured by both complete immersion in water, taken as control medium and in sulphuric acid $\left(\mathrm{H}_{2} \mathrm{SO}_{4}\right)$ solutions of $5 \%$ and $10 \%$ concentration for 7 , 14, 21 and 28 days. For each curing period, three (3) cubes were produced and the results were recorded, the average value was computed and used as stipulated in COREN [30] and clause 2013 of Nigeria General Specification for Road and Bridges [31].

\subsubsection{Slump test}

The slump test is a measure of the consistency or workability of fresh concrete. The test was carried out to determine the effect of cement partially replaced 
with PSA on the workability of concrete. The test was conducted in accordance with BS EN 12350: Part 2 [32] specifications.

\subsubsection{Compressive strength test}

Compressive strength test was carried out on both the control concrete specimens cured in water and specimens cured in sulphuric acid $\left(\mathrm{H}_{2} \mathrm{SO}_{4}\right)$ environment with concentrations of (5 and $10 \%$ concentration). Three cubes were tested at the ages of 7, 14, 21 and 28 days at the different levels. The compressive strength test was carried out on hardened cured concrete cubes. The test was conducted in accordance with BS EN 12390, Part 3 [33] specifications. The effect of different acid concentration on the compressive strength of the PSA - OPC blended concrete was evaluated by measuring the reduction in compressive strength using the expression in equation (1);

$$
\operatorname{RCS}(\%)=\frac{C_{w}-C_{S}}{C_{w}} \times 100
$$

Where RCS is reduction in compressive strength (\%), $\mathrm{C}_{\mathrm{w}}$ is the average compressive strength $\left(\mathrm{N} / \mathrm{mm}^{2}\right)$ of three specimens cured in water and $\mathrm{C}_{s}$ is the average compressive strength of three specimens exposed to sulphuric acidic environment.

\section{RESULTS AND DISCUSSION}

\subsection{Chemical and Physical Properties of Materials}

The chemical compositions of the PSA and OPC used in this study are shown in Table 1 . The summary results of particle size distribution for fine and coarse aggregates are shown in Figure 1 and 2, respectively. The specific gravity of PSA, cement, sand (fine aggregate) and coarse aggregate were found to be 2.56 , $3.13,2.4$ and 2.65, respectively. The specific gravity of PSA and cement implies that PSA is lighter than cement and more volume of PSA will be required for replacing equal weight of cement in concrete. PSA is a pozzolana and is classified as Class $\mathrm{C}$ in the classification of pozzolanas as given by ASTM C618-08 [34]

\subsection{Slump Test}

The results of the slump test carried out on the fresh concrete with varying percentage of PSA is presented in Table 2. The results indicate that the slump decreases with PSA content, which signifies that more water is required to maintain the same consistency as PSA content increases. A similar trend was observed by Olusola and Umoh [35] who reported a decrease in workability with PSA content.
Table 1: Chemical composition of Periwinkle shell ash and Ordinary Portland Cement

Elemental Oxides Weight (\%) PSA Weight (\%) OPC

$\begin{array}{ccc}\mathrm{CaO} & 29.54 & 61.14 \\ \mathrm{MgO} & 2.32 & 1.35 \\ \mathrm{~K}_{2} \mathrm{O} & 0.11 & 0.48 \\ \mathrm{SiO}_{2} & 42.32 & 21.40 \\ \mathrm{SO}_{3} & 0.31 & 2.53 \\ \mathrm{Na}_{2} \mathrm{O} & 0.43 & 0.24 \\ \mathrm{Al}_{2} \mathrm{O}_{3} & 11.6 & 5.03 \\ \mathrm{Fe}_{2} \mathrm{O}_{3} & 5.13 & 4.40 \\ \mathrm{P}_{2} \mathrm{O}_{5} & 0.01 & - \\ \mathrm{TiO}_{2} & 0.042 & - \\ \mathrm{LOI} & 5.5 & 1.29\end{array}$

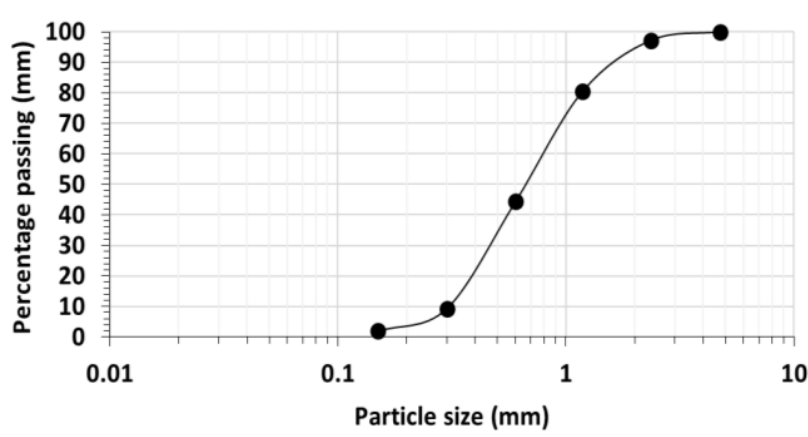

Figure 1: Particle size distribution for fine aggregate

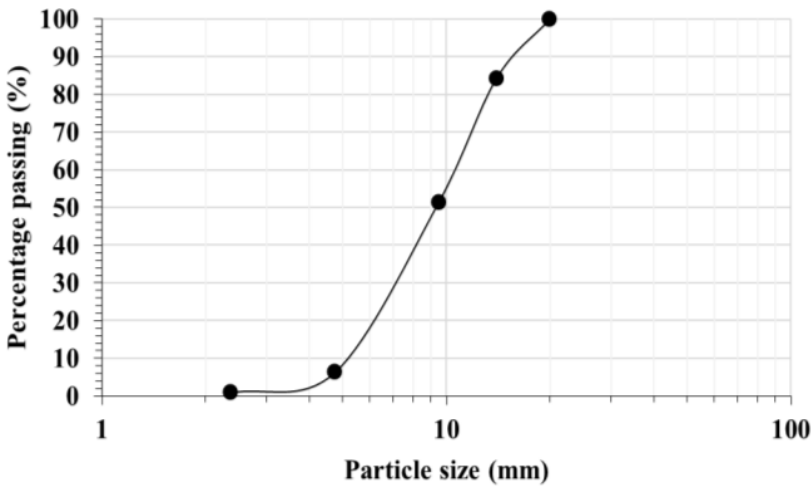

Figure 2: Particle size distribution for coarse aggregate

Table 2: Slump test result of PSA-OPC blended concrete

\begin{tabular}{cc}
\hline Percentage replacement (\%) & Slump $(\mathrm{mm})$ \\
\hline 0 & 29 \\
5 & 28 \\
10 & 25 \\
15 & 23 \\
20 & 21
\end{tabular}

\subsection{Compressive Strength of Specimens Cured in Potable Water $\left(0 \% \mathrm{H}_{2} \mathrm{SO}_{4}\right)$}

The mean compressive strength of concrete produced with cement replaced with $0,5,10,15$ and $20 \%$ PSA cured in potable water and at different curing ages of 7 , 14, 21 and 28 days is shown in Figure 1. However, at all replacement levels, the compressive strength generally 
increased with curing age and decreased with PSA content. This result is consistent with the behaviour of supplementary cementitious materials (SCMs) [36, 37, 38]. It was observed that at 7 days hydration period, the compressive strength of specimens immersed in potable water decreased with increase in PSA replacement levels of $0,5,10,15$, and $20 \%$. The early attainment of strength could be as a result of cement hydration [36].

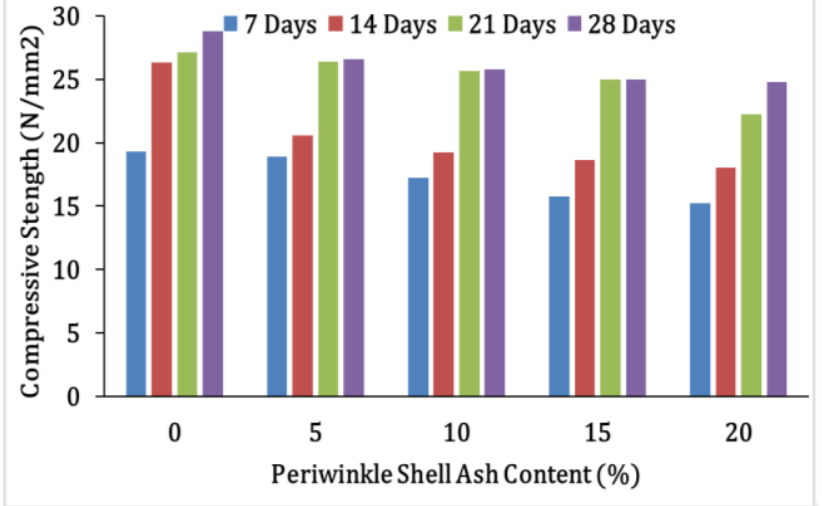

Figure 1: Variation of compressive strength with varying Percentages of PSA contents for different curing ages for cubes cured in potable water $(0 \%$ $\mathrm{H}_{2} \mathrm{SO}_{4}$ ).

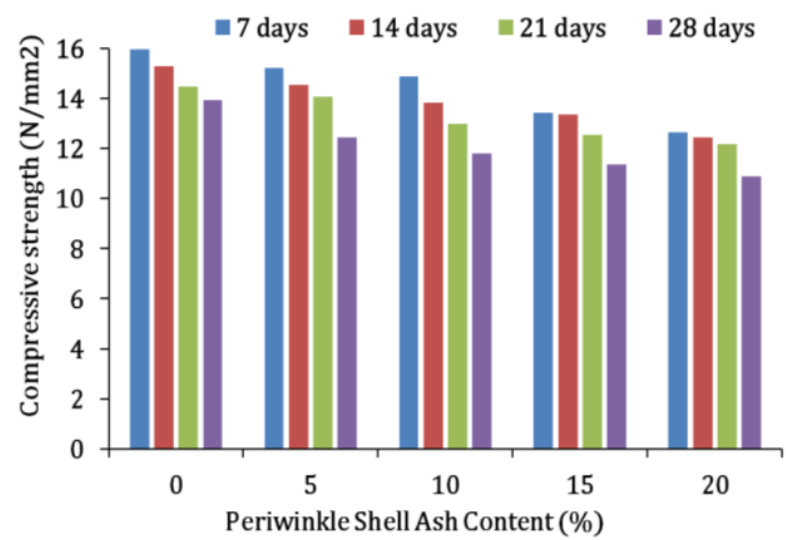

Figure 2: Variation of compressive strength of blended cement - PSA concrete cubes with PSA replacement cured in $5 \% \mathrm{H}_{2} \mathrm{SO}_{4}$

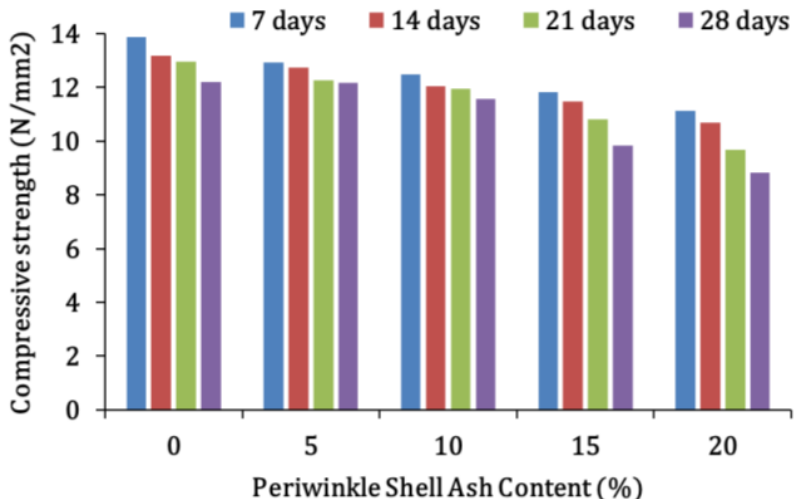

Figure 3: Variation of compressive strength of blended cement - PSA concrete cubes with PSA replacement cured in $10 \% \mathrm{H}_{2} \mathrm{SO}_{4}$
At 14 days hydration period, the compressive strength of control specimen (that is $0 \%$ PSA) exceeded the target design strength of $25 \mathrm{~N} / \mathrm{mm}^{2}$ while specimens of cement blended with periwinkle shell ash showed a decreasing trend in compressive strength with increased PSA replacement. The strength development at 14 days for both $15 \%$ and $20 \%$ PSA replacement satisfies the $60-75 \%$ of the design strength as stipulated by lllston [39]. The control specimen gained more strength faster compared to the specimens containing PSA which was slow. This is expected because of the release of calcium hydroxide from cement hydration $[15,7,8,9]$. The results at 21 and 28 days hydration showed little increase in compressive strength for all PSA replacement.

\subsection{Compressive Strength of Specimens Cured in Sulphuric Acid Solutions.}

The results of compressive strength of concrete specimen produced with cement partially replaced with PSA and immersed in sulphuric acid solution of different concentrations (5 and $10 \% \mathrm{H}_{2} \mathrm{SO}_{4}$ ) is presented in Figure 2 and 3. Generally, for cubes with various replacement levels and cured in $\mathrm{H}_{2} \mathrm{SO}_{4}$ from 7 to 28 days, there was a reduction in compressive strength. The compressive strength of the specimens immersed in different acid concentrations (5 and $10 \%$ $\mathrm{H}_{2} \mathrm{SO}_{4}$ ) decreased with curing age. This result could be attributed to the deteriorating effect of acid on concrete with curing period [40].

The variation in reduction of compressive strength with PSA content, curing age and acid medium is shown in Table 3. It was observed that the reduction in compressive strength of specimens immersed in sulphuric acid solution increases with increase in sulphuric acid concentration (5 and $10 \% \mathrm{H}_{2} \mathrm{SO}_{4}$ ). The reduction in compressive strength became very high with increase in exposure condition particularly at 28 days. This could be as a result of the deteriorating effect of acid on the concrete cubes which became more pronounced. The effect is that, the durability of the concrete is reduced. Specimens with $20 \%$ PSA content immersed for 28 days, cured in fresh water, 5 and $10 \%$ concentration of sulphuric acid attained a compressive strength of $24.80 \mathrm{~N} / \mathrm{mm}^{2}, 10.89 \mathrm{~N} / \mathrm{mm}^{2}$ and 8.81 $\mathrm{N} / \mathrm{mm}^{2}$ respectively. This signifies the highest RCS of about 56.08 and $64.47 \%$ for 5 and $10 \% \mathrm{H}_{2} \mathrm{SO}_{4}$ respectively (Table 3 ). The increase in reduction of compressive strength with curing age could be attributed to the fact that, as curing age increases, the concentration of the acid also increased because of the 
evaporation of the curing water thus making the curing media more acidic. This implies an increase in the rate of deterioration reaction in line with Le Chaterlier's principle and the result agrees with the results of experimental work by Reddy et al [41]. Furthermore, the high reduction in compressive strength with increase in acid concentration is associated with the reaction of acid with the alkaline hydration products of cement/concrete matrix to form $\mathrm{CaSO}_{4 \cdot 2} \mathrm{H}_{2} \mathrm{O}$ (gypsum)

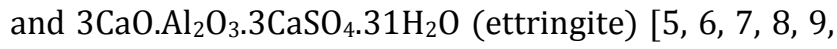
11]. These products are known to possess low and weak structural strength [10].

\subsection{Statistical Analysis of Variance 3.5.1 Analysis of Variance}

The two-way statistical analysis of variance (ANOVA) without replication on the $7,14,21$ and 28 days compressive strength results at 95\% confidence level (that is $\alpha=0.05$ ) is presented in table 4. The PSA replacements and concentration of curing mediums were considered as source of variations of the compressive strength property. The results showed that it was statistically significant, SS within curing range. This implies that variations in PSA/cement contents and concentration of curing mediums had significant effects on the compressive strength of concrete cubes obtained at $7,14,21$ and 28 days respectively. Generally the values of $\mathrm{F}_{\mathrm{CAL}}$ were observed to be more than three times greater than the $\mathrm{F}_{\text {CRIT }}$ and p-values far less than 0.05 (Table 4).

\section{CONCLUSION}

The compressive strength of concrete produced with cement partially replaced with PSA in different concentrations of sulphuric acid has been studied. Concrete made from cement blended with periwinkle shell ash possesses relative low compressive strength when immersed in sulphuric acid solution. The statistical analysis of variance showed that the sulphuric acid concentrations, PSA contents and curing age have effect on the compressive strength of concrete produced with cement blended with PSA exposed to different concentration of $\mathrm{H}_{2} \mathrm{SO}_{4}$. It can therefore be said that PSA replacement did not mitigate the effect of chemical attack caused by $\mathrm{H}_{2} \mathrm{SO}_{4}$ on concrete.

Table 3: Compressive strength and reduction in compressive strength of cubes cured in potable water and sulphuric acid media (5 and $10 \%$ )

\begin{tabular}{ccccccc}
\hline $\begin{array}{c}\text { Curing } \\
\text { age }\end{array}$ & $\begin{array}{c}\text { PSA content } \\
(\%)\end{array}$ & $\begin{array}{c}\text { Cured in Potable } \\
\text { water }\end{array}$ & $\begin{array}{c}\text { Cured in } 5 \\
\% \mathrm{H}_{2} \mathrm{~S}_{4}\end{array}$ & $\begin{array}{c}\text { Cured in } 10 \\
\% \mathrm{H}_{2} \mathrm{SO}_{4}\end{array}$ & RCS $5 \% \mathrm{H}_{2} \mathrm{~S}_{4}$ & ${\mathrm{RCS} 10 \% \mathrm{H}_{2} \mathrm{~S}_{4}}$ \\
\hline 7 & 0 & 19.29 & 15.99 & 13.86 & 17.11 & 28.15 \\
& 5 & 18.88 & 15.23 & 12.91 & 19.31 & 31.60 \\
& 10 & 17.23 & 14.88 & 12.48 & 13.67 & 27.57 \\
& 15 & 15.74 & 13.42 & 11.82 & 14.71 & 24.88 \\
& 20 & 15.20 & 12.65 & 11.14 & 16.78 & 26.74 \\
\hline 14 & 0 & 26.31 & 15.31 & 13.19 & 41.81 & 49.87 \\
& 5 & 20.56 & 14.55 & 12.73 & 29.21 & 38.07 \\
& 10 & 19.26 & 13.83 & 12.05 & 28.17 & 37.42 \\
& 15 & 18.65 & 13.37 & 11.48 & 28.31 & 38.45 \\
& 20 & 18.05 & 12.45 & 10.68 & 31.02 & 40.83 \\
\hline 21 & 0 & 27.15 & 14.47 & 12.95 & 46.71 & 52.29 \\
& 5 & 26.40 & 14.08 & 12.27 & 46.67 & 53.52 \\
& 10 & 25.67 & 12.99 & 11.94 & 49.39 & 53.48 \\
& 15 & 24.97 & 12.56 & 10.81 & 49.71 & 56.70 \\
& 20 & 22.22 & 12.19 & 9.68 & 45.14 & 56.46 \\
\hline 28 & 0 & 28.80 & 13.95 & 12.21 & 51.56 & 57.62 \\
& 5 & 26.66 & 12.44 & 12.15 & 53.35 & 54.42 \\
& 10 & 25.79 & 11.81 & 11.58 & 54.21 & 55.12 \\
& 15 & 24.98 & 11.36 & 9.84 & 54.51 & 60.60 \\
& 20 & 24.80 & 10.89 & 8.81 & 56.08 & 64.47 \\
\hline
\end{tabular}


Table 4: Results of two - way analysis of variance for compressive strength of PSA/cement concrete

\begin{tabular}{|c|c|c|c|c|c|c|}
\hline Compressive strength & Source of variation & DOF & $\mathrm{F}_{\mathrm{CAL}}$ & P-value & $\mathrm{F}_{\text {CRIT }}$ & Remark \\
\hline \multirow[t]{2}{*}{7 days } & PSA content & 4 & 26.94 & 0.000108 & 3.838 & $\mathrm{~F}_{\mathrm{CAL}}>\mathrm{F}_{\mathrm{CRIT}} \mathrm{SS}$ \\
\hline & Acid conc. & 2 & 135.63 & $6.73 \mathrm{E}-07$ & 4.459 & $\mathrm{~F}_{\mathrm{CAL}}>\mathrm{F}_{\mathrm{CRIT}} \mathrm{SS}$ \\
\hline \multirow[t]{2}{*}{14 days } & PSA content & 4 & 4.36 & 0.036515 & 3.838 & $\mathrm{~F}_{\mathrm{CAL}}>\mathrm{F}_{\mathrm{CRIT}} \mathrm{SS}$ \\
\hline & Acid conc. & 2 & 47.92 & $3.52 \mathrm{E}-05$ & 4.459 & $\mathrm{~F}_{\mathrm{CAL}}>\mathrm{F}_{\mathrm{CRIT}} \mathrm{SS}$ \\
\hline \multirow[t]{2}{*}{21 days } & PSA content & 4 & 16.30 & 0.000652 & 3.838 & $\mathrm{~F}_{\mathrm{CAL}}>\mathrm{F}_{\mathrm{CRIT}} \mathrm{SS}$ \\
\hline & Acid conc. & 2 & 825.27 & $5.41 \mathrm{E}-10$ & 4.459 & $\mathrm{~F}_{\mathrm{CAL}}>\mathrm{F}_{\mathrm{CRIT}} \mathrm{SS}$ \\
\hline \multirow[t]{2}{*}{28 days } & PSA content & 4 & 22.86 & 0.000196 & 3.838 & $\mathrm{~F}_{\mathrm{CAL}}>\mathrm{F}_{\mathrm{CRIT}} \mathrm{SS}$ \\
\hline & Acid conc. & 2 & 1344.22 & $7.75 \mathrm{E}-11$ & 4.459 & $\mathrm{~F}_{\mathrm{CAL}}>\mathrm{F}_{\mathrm{CRIT}} \mathrm{SS}$ \\
\hline
\end{tabular}

DOF Degree of freedom, SS Statistically significant, conc. Concentration

\section{REFERENCES}

[1] Bradan, B., Yazici, H., Ün, H., "Durability of Reinforced Concrete Structures" University of Dokuz Eylul, Izmir, Turkey, 2002.

[2] Neville, A. M. Properties of Concrete, $5^{\text {th }}$ edition, New York: Pitman, 2000.

[3] ACI Committee 201. 2R, "Guide to Durable Concrete", American Concrete Institute, Farmington Hills, Michigan, 2003.

[4] Attiogbe, E. K and Rizkalla, S. H. "Response of Concrete to Sulfuric Acid Attack". ACI Materials Journal, vol. 85, no. 6, pp 481- 488, 1988.

[5] Zivica, V., Palou, M., Krizmaand, M. and Bagel, L. "Acidic attack of cement based materials under the common action of high ambient temperature and pressure". Construction and Building Materials, 36, pp 623 - 629, 2012.

[6] Zivica, V. and Bajza, A. Acid Attack on Cement based Materials - A Review, part 1, Construction and Building Materials, vol. 15, no. 8, pp 331-340, 2001

[7] Neville, A. M. Properties of concrete. Fourth edition, Pearson Prentice Hall, 2008.

[8] Larreur-Cayol, S., Bertron, A. and Escadeillas, G. "Degradation of cement-based materials by various organic acids in agro-industrial wastewaters". Cement and Concrete Research, vol. 41, no. 8, pp 882 - 892, 2011.

[9] Yuan, H., Dangla, P., Chatellier, P. and Chaussadent, T. "Degradation modelling of concrete submitted to sulphuric acid attack". Cement and Concrete Research, 53, pp 267 - 277, 2013.

[10] Monteny, N., Debelie E., Vinke, V. And Taerwe, L. "Chemical and microbiological tests to simulate sulphuric acid corrosion of polymer - modified concrete. Cement and Concrete Research, vol. 31, no. 9, pp 1359-1365, 2001.
[11] Olonade, K. A., Olajumoke, A. M., Omotosho, A. O., and Oyekunle, F. A. "Effects of sulphuric acid on the compressive strength of blended cement / cassava peel ash concrete" Construction Materials and Structures, S.O. Ekolu et al. (Eds.), IOS Press, 764 - 771, 2014.Doi: 10.3233/978-161499-466-4-764.

[12] Mindess, S. and Young, J. F. Concrete, Prentice Hall, Englewood Cliffs, 1981.

[13] Ookame, Y., Hatano, Y and Kawai, K. "Study on long term concrete deterioration due to sulfuric acid". Proceedings of the Third International Conference on Sustainable Construction Materials and Technologies, Kyoto Research Park, Kyoto, Japan, August 18th - 21st, 2013.

[14] Sai-Prasad, P. V. and Jha, K. "High Performance Concrete", Project work done for course No.624Sr. professional course (Bridges and General), 2006.

[15] Mehta, P. K. and Monteiro, P. J. M., Concrete: microstructure, properties and materials $3^{\text {rd }}$ Ed., New Delhi, McGraw-Hill publishing company Ltd., 2006

[16] Soeda, M., Yamato, T., and Emoto, Y. "Influence of Combined Admixture on the Chemical Resistance of Concrete." Cement Science and Concrete Technology, No.45, pp 228-233, 1991.

[17] Ahmed, S. R and Munirudrappa, N. "Effect of sulphuric acid on plasticized concrete". Indian Journal of Engineering and Materials Sciences. Vol. 5, pp 291-294, 1998.

[18] Siad, H., Mesbah, H. A., Khelafi, H., KamaliBernard, S. and Mouli, M. "Effect of mineral admixture on resistance to sulphuric and hydrochloric acid attacks in self- compacting concrete". Can. J. Civ. Eng. Vol. 37, no. 3, pp 441449, 2010.

[19] Adesanya, D. A. and Raheem, A. A. "A study of the permeability and acid attack of corn cob ash blended cements". Constr. Build. Mater., vol. 24, no. 3, pp 403-409, 2010.

Vol. 37, No. 2, April 2018 
[20] Sahmaran, M., Kasap, O., Duru, K. and Yaman, I. O. "Effects of mix composition and water - cement ratio on the sulphate resistance of blended cements", Cement and Concrete Composites, vol. 29, no. 3, pp 159-167, 2007.

[21] Dahunsi, B. I. O. and Bamisaye, J. A. "Use of periwinkle shell ash (PSA) as partial replacement for cement in concrete." Proceedings Nigerian Materials Congress and Meeting of Nigerian Materials Research Society, Akure, Nigeria, Nov. 11 - 13, 2002, pp 184-186.

[22] Koffi, N. E. "Compressive Strength of Concrete Incorporating Periwinkle Shell Ash", B.Sc Project, Department of Building, University of Uyo, Nigeria, 2008.

[23] Job, O. F., Umoh, A. A. and Nsikak, S. C. "Engineering Properties of Sandcrete Blocks Containing Periwinkle Shell Ash and Ordinary Portland cement", International Journal of Civil Engineering, vol. 1, no.1, pp, 18-24, 2009.

[24] Etim, R. K., Attah, I. C. and Okon, B. B. "Assessment of Periwinkle Shell Ash Blended Cement Concrete in Crude Oil Polluted Environment" FUW Trends in Science \& Technology Journal, Vol. 2 No. 2 pp. 879 - 885, 2017.

[25] Umoh, A. A. and Olusola, K. O. "Effect of Different Sulphate Types and Concentrations on Compressive Strength of Periwinkle Shell Ash Blended Cement Concrete". International Journal of Engineering \& Technology, Vol. 12, no. 5, pp $10-17,2012$.

[26] Nigerian Industrial Standards 444:1 Quality Standards for Ordinary Portland Cement - Part 1: Composition, Specifications and Conformity criteria for common cements, Lagos, Standard Organisation of Nigeria (SON), 2003.

[27] British Standard Institution, BS EN 12620. "Aggregates for Concrete" British Standard Institution, London, 2002.

[28] British Standard Institution "Grading limits for Fine Aggregates" BS 882 Part 2, British Standard Institution, London, 1992.

[29] ASTM C1602-12, Standard Specification for Mixing Water used in the Production Hydraulic Cement Concrete, ASTM International, West Conshohocken, PA, 2012.
[30] Council for the Regulation of Engineering in Nigeria "Concrete Mix Design Manual”, Special Publication No. COREN/2017/016/RC, First Edition: August, 2017

[31] Nigeria General Specification for Road and Bridges “Federal Ministry of Works." 1997.

[32] British Standard Institution, BS EN 12350, Part 2, "Testing fresh concrete: Slump test", London, British Standard Institution, 2009.

[33] British Standard Institution, BS EN 12390, Part 3. "Methods for Determination of Compressive Strength" British Standard Institution, London, 2009.

[34] ASTM C618 "Standard Specification for Coal fly ash and raw or Calcined Natural Pozzolan for use in concrete" (ASTMC618-08), West Conshohocken, PA: ASTM International, 3pp. 2008.

[35] Olusola, K. O. and Umoh, A. A. Strength Characteristics of Periwinkle Shell Ash Blended with Cement Concrete. International Journal of Architecture, Engineering and Construction, vol. 1, no. 4, pp 213-220, 2012.

[36] Shetty, M. S. Concrete technology: Theory and practice: S. Chand, 2005.

[37] Olafusi, O. and Olutoge, F. "Strength properties of corn cob ash concrete", Journal of Emerging trends in Engineering and Applied Sciences, vol. 3, no. 2, pp 297-301, 2012.

[38] Adesanya, D. A. and Raheem A. A., "A study of the workability and compressive strength characteristics of corn cob ash blended cement concrete", Construction and Building Materials, vol. 23, no. 1, pp 311-317, 2009.

[39] Illston, J. M. Construction materials: Their nature and behaviour $2^{\text {nd }}$ ed. London, Chapman and hall, pp 518, 1994.

[40] Turkel, S., Felekoglu, B. and Dulluc, S. "Influence of various acids on the physio-mechanical properties of pozzolanic cement mortars". Sadhana, vol. 32, no. 6, pp 683-691, 2007.

[41] Reddy, B. M, Rao, H. S. and George, M. P. "Effect of Hydrochloric Acid on Blended Cement (Fly Ash Based) and Silica Fume Blended Cements and their Concretes", International Journal of Science and Technology, vol. 1, no. 9, pp 467-480, 2012. 